\title{
Effect of stocking density on social, feeding, and lying behavior of prepartum dairy animals
}

\author{
K. M. Lobeck-Luchterhand, ${ }^{*}$ P. R. B. Silva, ${ }^{*} \dagger$ R. C. Chebel, ${ }^{*} \dagger$ and M. I. Endres ${ }^{* 1}$ \\ *Department of Animal Science, and \\ †Department of Veterinary Population Medicine, University of Minnesota, St. Paul 55108
}

\begin{abstract}
The objectives of this study were to determine the effects of prepartum stocking density on social, lying, and feeding behavior of dairy animals and to investigate the relationship between social rank and stocking density. In total, 756 Jersey animals were enrolled in the study approximately 4 wk before expected calving date. This study used 8 experimental units (4 replicates $\times 2$ pens/ treatment per replicate), and at each replicate, one pen each of nulliparous and parous (primiparous and multiparous) animals per treatment was enrolled. The 2 treatments were $80 \%$ stocking density (80D, 38 animals per pen; each pen with 48 headlocks and 44 stalls) and $100 \%$ stocking density (100D, 48 animals per pen). Parous animals were housed separately from nulliparous animals. Animals at $254 \pm 3 \mathrm{~d}$ of gestation were balanced for parity (parous vs. nulliparous) and projected 305-d mature-equivalent milk yield (only parous animals) and randomly assigned to either $80 \mathrm{D}$ or $100 \mathrm{D}$. Displacements from the feed bunk were measured for 3 $\mathrm{h}$ after fresh feed delivery on d 2, 5, and 7 of each week. Feeding behavior was measured for 24 -h periods (using 10-min video scan sampling) on d 2, 5, and 7 on wk 1 of every replicate and d 2 and 5 for the following 4 wk. A displacement index (proportion of successful displacements from the feed bunk relative to all displacements the animal was involved in) was calculated for each animal and used to categorize animals into ranking categories of high, middle, and low. Seventy nulliparous and 64 parous focal animals in the $80 \mathrm{D}$ treatment and 89 nulliparous and 74 parous focal animals in the 100D were used to describe lying behavior (measured with data loggers). Animals housed at 80D had fewer daily displacements from the feed bunk than those housed at $100 \mathrm{D}(15.2 \pm 1.0$ vs. $21.3 \pm 1.0$ per day $)$. Daily feeding times differed between nulliparous and parous animals at the 2 stocking densities. Nulliparous $80 \mathrm{D}$ animals spent $12.4 \pm 5.0$ fewer minutes per day feeding
\end{abstract}

Received June 16, 2014.

Accepted October 9, 2014.

${ }^{1}$ Corresponding author: miendres@umn.edu than nulliparous 100D animals, whereas 100D parous animals tended to spend $7.6 \pm 4.5$ fewer minutes per day feeding than $80 \mathrm{D}$ parous animals. The 2 treatments were not different in the number of lying bouts or lyingbout duration; lying time was longer for 100D on $\mathrm{d}$ $-33,-29$, and -26 and shorter on $\mathrm{d}-7,-5$, and 0 than $80 \mathrm{D}$. The interaction between treatment, parity, and social rank was associated with lying and feeding times. In summary, animals in the $80 \mathrm{D}$ treatment had a lower number of displacements from the feed bunk and spent more time lying down near parturition than 100D animals, and 80D nulliparous animals had reduced daily feeding time compared with 100D nulliparous animals. Although these results showed some potential behavior benefits of a prepartum stocking density of $80 \%$ compared with $100 \%$, observed changes were small. However, greater stocking density cannot be recommended; more research is needed to evaluate the effects of stocking densities greater than 100\% and with other breeds of cattle besides Jersey.

Key words: prepartum cow, stocking density, feeding behavior, lying behavior, social behavior

\section{INTRODUCTION}

The transition dairy cow is one of the highest-risk animals for falling ill or dying on the dairy farm. Typically the transition period is described as 3 wk before and after calving (Grummer, 1995). During this period cows experience physiological, immune, and nutritional changes making the cow at risk for metabolic and infectious diseases (Goff and Horst, 1997). Up to $25 \%$ of cows are culled or die during the first 60 DIM (Godden et al., 2003), which may be attributed to an unsuccessful transition period. Concern over animal well-being and reduction on farm profitability due to morbidity and mortality losses have stimulated more research in the area of transition-cow management and behavior to improve transition-cow success.

Dry matter intake decreases 3 wk before calving (Hayirli et al., 2002), and more severe reductions in DMI may put the cow at risk for metabolic disorders such as ketosis and fatty liver. Cows will typically oc- 
cupy $80 \%$ of the feed-bunk linear space during the peak feeding time after fresh feed delivery (Huzzey et al., 2006; Nordlund et al., 2006). The current industry recommendations for prepartum freestall-housed dry cows is to provide a minimum of $0.76 \mathrm{~m}$ of linear bunk space per cow (or stock at $80 \%$ of 0.61 -m headlocks) with at least one stall per cow for resting space (Nordlund et al., 2006). In a field study with prepartum nulliparous and parous animals housed together, it was reported that for every $10 \%$ increase in stocking density above $80 \%$ of headlocks, milk yield decreased $0.7 \mathrm{~kg} / \mathrm{d}$ for first-lactation cows in that lactation (Oetzel et al., 2007). Increasing linear feeding space has been observed to reduce competition at the feed bunk (Huzzey et al., 2006) and may benefit lower-ranking animals. The number of aggressive interactions was fewer and feeding activity during the $90 \mathrm{~min}$ after fresh feed delivery increased when lactating dairy cattle had access to $1.0 \mathrm{~m}$ of feeding space per cow compared with $0.5 \mathrm{~m}$ per cow (DeVries et al., 2004). Krawczel et al. (2012) reported changes in social behavior of lactating cows with a linear increase in displacements from the feed bunk as stall stocking density increased from 100 to $142 \%$, but they observed no differences in feeding or rumination time.

Two resources highly valued by cows are lying and feeding space. Lactating cows spend approximately 12 to $13 \mathrm{~h} / \mathrm{d}$ lying down (Fregonesi et al., 2007) and 5 to $6 \mathrm{~h} / \mathrm{d}$ feeding (Val-Laillet et al., 2008). Lying has a higher priority for cows than eating and social contact when these behaviors are restricted (Munksgaard et al., 2005). Lying time was linearly reduced when stocking density increased from 100 to 150\% (Fregonesi et al., 2007). Krawczel et al. (2012) reported lying time was reduced for stocking densities of 131 and $142 \%$ compared with 100 or $113 \%$. Late-lactation cows stocked at $100 \%$ of stalls spent less time lying down compared with cows stocked at $25 \%$ of stalls (Telezhenko et al., 2012).

The feed bunk can be an area of competition causing changes in feeding behavior. Multiparous cows in a competitive feed environment (2 cows per 1 feed bin) had a shorter feeding time and ate at a faster rate for up to 2 wk postcalving, whereas the feeding behavior of primiparous cows did not differ (Proudfoot et al., 2009). In other studies, when the number of cows to feed bin increased, the competitively fed cows did not differ in DMI or daily feeding time, but cows had fewer meals per day with the tendency of larger and longer meals (Olofsson, 1999; Hosseinkhani et al., 2008). Additionally, as competition at the feed bunk increased, idle standing time also increased (Olofsson, 1999), which has been associated with an increase in lameness prevalence (Cook et al., 2004).
Only a few studies have evaluated stocking density during the prepartum period and in conditions similar to commercial dairies. Data collected by Oetzel et al. (2007) demonstrated a decrease in milk yield for primiparous cows in a mixed pen with multiparous cows when prefresh pen stocking densities exceeded $80 \%$. Huzzey et al. (2012) reported greater DMI, plasma nonesterified fatty acids, and glucose concentrations with a tendency for greater fecal cortisol metabolite for cows housed at a higher pen stocking density (1 stall per cow and $0.67 \mathrm{~m}$ of linear feed bunk space compared with 0.5 stall per cow and $0.34 \mathrm{~m}$ of linear feed bunk space). To our knowledge no research on stocking density during the prepartum period has been conducted with Jersey cows, and results could differ from Holstein cows.

The objectives of this study were to determine whether increasing stocking density in a commercial Jersey dairy farm from 80 to $100 \%$ would affect social, feeding, and lying behavior of prepartum nulliparous and parous dairy animals and to investigate whether behaviors varied among animals of different social rank at the 80 or $100 \%$ stocking density.

\section{MATERIALS AND METHODS}

\section{Animals and Housing}

A total of 756 nulliparous and parous (primiparous and multiparous) Jersey animals were allocated to 2 treatments from October 2012 to March 2013. The study was conducted at a large commercial dairy farm (6,400 lactating dairy cows) in south-central Minnesota. Prepartum animals were provided a TMR (balanced to meet nutrient requirements) once daily at approximately $0700 \mathrm{~h}$ and fed from a feed alley by headlocks. Four experimental pens housing either 38 or 48 animals each were used in each replicate period with 2 pens per treatment enrolled at each replicate. Two pens (one per each treatment) housed primiparous and multiparous cows together referred to as parous, and 2 pens (one per each treatment) housed nulliparous animals. All experimental pens had the same measurements of $31.7 \times$ $11.0 \mathrm{~m}$ and had 44 deep sand bedded freestalls (229-cm length $\times 107-\mathrm{cm}$ width $\times 114$-cm height) with a headto-head configuration and forty-eight 0.61-m headlocks. Sand bedding was added once weekly, and pens were scraped once daily. Two water troughs were located in the pen and measured $366 \times 56 \mathrm{~cm}$. One water trough was located at the end of the bank of freestalls, and a shared water trough was located between the treatment pen and an adjacent nonexperimental pen. After each replicate, treatment within parity (nulliparous or parous) was switched to the opposite pen to prevent location bias. 
When animals demonstrated signs of calving, farm personnel moved them to an individual box stall. At d 1 after calving cows were moved into a freestall pen with 240 stalls and 260 headlocks, stocked at $100 \%$ based on the number of stalls for $21 \mathrm{~d}$. Parous and nulliparous animals were housed separately during the first 21 DIM.

\section{Experimental Treatments and Design}

Animals at $254 \pm 3 \mathrm{~d}$ from expected calving date were balanced for parity (parous vs. nulliparous) and projected 305-d mature-equivalent milk yield (parous animals only) and were allocated to $80 \%$ (80D; 38 animals per pen; each pen with 48 headlocks and 44 stalls) or 100\% (100D; 48 animals per pen) stocking density. Animals were required to have a BCS between 2 and 4 (1-5 scale; $1=$ emaciated, $5=$ obese $)$ and a locomotion score $\leq 3$ (1-5 scale; $1=$ normal gait, $5=$ severely lame) or were not included in the study. A total of 418 animals were enrolled in 100D and 338 animals in $80 \mathrm{D}$ over the study period. Pens were stocked twice weekly (on Mondays and Thursdays), and groups of 2 to 15 animals (median $=9$ animals) were moved to the $80 \mathrm{D}$ and $100 \mathrm{D}$ pens to reestablish the targeted stocking density.

\section{Behavior Measurements}

All enrolled animals were identified with a unique alphanumeric symbol on their back using permanent hair dye either in black or blonde. Hair dye was applied at either $\mathrm{d} 0$ before animals moving to the treatment pens or d 1.

Social Behavior. To observe social interactions while feeding, we used 3 video cameras (Weldex, Cypress, CA) per pen located $5 \mathrm{~m}$ above the feed bunk and connected to a digital video recording system (Channel Visions, Costa Mesa, CA). Displacements from the feed bunk were measured continuously during $3 \mathrm{~h}$ following fresh feed delivery $(0700 \pm 0100 \mathrm{~h})$ on $\mathrm{d} 2$, 5 , and 7 of each 5-wk observation period. Previous research has shown that displacements from the feed bunk for $2 \mathrm{~h}$ following feeding explained the majority of the variation associated with displacements recorded over a full $24 \mathrm{~h}\left(\mathrm{R}^{2}=0.96 ; P<0.001\right.$; Collings et al., 2011). Observation days were chosen based on days that animals were not scheduled to be locked up by farm staff or research personnel. From continuous video observation, an interaction between 2 animals was considered a displacement from the feed bunk when physical contact initiated by one animal caused the receiving animal to stop feeding, back out, and entirely remove its head from the headlock (Endres et al., 2005). Displacements from the feed bunk were summed daily for the entire 5-wk observation period. A displacement index (DI) was calculated (Galindo and Broom, 2000) as the proportion of successful displacements from the feed bunk relative to all displacements in which the animal was involved. An overall social rank was calculated for each animal during its time in the pen. Animals with a DI $>0.6$ were classified as high ranking, 0.4 to 0.6 were middle ranking, and animals with a DI $<0.4$ were classified as low ranking. Although we acknowledge the group composition in the pens was dynamic, it is suggested that this DI represented the typical rank of the cow.

Feeding Behavior. Feeding time for all marked animals in the pen was measured using 10-min video scan sampling for 24-h periods (Endres et al., 2005) on $\mathrm{d} 2,5$, and 7 for wk 1 of each replicate and at d 2 and 5 for wk 2 to 5 . An animal was considered eating when her ears were on the feed alley side of the headlocks. Video observations ceased when the animal left the prepartum-period treatment pen.

Lying Behavior. A total of 297 focal animals were used to describe pen lying behavior. The 100D and $80 \mathrm{D}$ pens averaged $20 \pm 3$ and $17 \pm 3$ (mean $\pm \mathrm{SD}$ ) focal animals per pen, respectively. Lying time, lying bouts, and lying-bout duration were measured using HOBO Pendant G data loggers (Onset, Bourne, MA). Data loggers were set to collect lying behavior at 30-s intervals (Ledgerwood et al., 2010) and placed on the right hind leg of the cow $1 \mathrm{~d}$ after entrance into the pen. Loggers were kept on the cow for $12 \mathrm{~d}$ and removed for $7 \mathrm{~d}$ and reattached for another $12 \mathrm{~d}$ or until the cow calved. Animals that calved early had loggers removed within $2 \mathrm{~d}$ of calving and data after calving was removed from the data set. Daily lying times, frequency of lying bouts, and lying-bout duration were computed for each cow using a macro in SAS (SAS Institute Inc., Cary, NC) developed by N. Chapinal (University of British Columbia, Vancouver, BC, Canada, personal communication).

\section{Statistical Analysis}

The UNIVARIATE procedure of SAS was used to examine normality and detect the presence of outliers for number of displacements, feeding times, and lying behavior by pen. A linear mixed model (MIXED procedure, SAS) was built to evaluate the effect of close-up prepartum feed-bunk stocking density and the outcome variables of daily displacements from the feed bunk, daily feeding time, and lying behavior (daily lying time, number of lying bouts per day, and lying-bout duration). Pen was used as the experimental unit. The structure of covariance (auto-regressive, unstructured, or compound symmetry) was chosen according to the 
Bayesian Akaike information criterion for repeated measurements. A repeated statement included day and cow nested within replicate as the subject. Pen was used as a random effect for social, feeding, and lying behaviors. Covariates examined for social behavior included treatment (80D vs. 100D), parity (nulliparous vs. parous), average day relative to calving, replicate (1-4), and day of replicate (d 1-35). Covariates examined for lying and feeding behavior included treatment, parity, day relative to calving, day of replicate, and the interaction of treatment $x$ day relative to calving. Additionally, the interaction of parity (nulliparous and parous) and treatment was examined for all models, and if not significant, results were combined. Least squares means and standard errors were computed using the LSMEANS statement in the MIXED procedure. Least squares means comparisons were separated with PDIFF.

An additional analysis was conducted to determine whether animals of different social ranking behaved differently at the 2 different stocking densities. Daily feeding times and lying behavior were analyzed with a mixed-effects linear regression model using PROC MIXED of SAS (v. 9.2). Cow was treated as a random effect $(\mathrm{df}=722)$. The repeated measures of day were modeled for each cow based on Bayesian information criterion. Covariates included treatment, parity, social category (high, middle, or low ranking), and day relative to calving. The interactions of social rank, treat- ment, and parity were examined. Least squares means and standard errors were separated with PDIFF.

\section{RESULTS}

Daily average stocking densities based on number of headlocks or stalls were different between treatments (Figure 1; $P<0.01$ ). Headlocks were stocked on average at $74.1 \pm 0.4 \%$ and $94.5 \pm 0.3 \%$ for the $80 \mathrm{D}$ and $100 \mathrm{D}$ treatments, respectively; stalls were stocked on average at $80.8 \pm 0.4 \%$ and $103.1 \pm 0.4 \%$ for the $80 \mathrm{D}$ and $100 \mathrm{D}$ treatments, respectively. Overall, the targeted stocking density difference of 20 percentage units between the 2 treatments was achieved during the study period.

\section{Social Behavior}

Parity or parity $\times$ treatment interaction had no effect on displacements from the feed bunk; therefore, results were combined. Animals housed in the $80 \mathrm{D}$ feed bunk stocking density averaged $15.2 \pm 1.0$ displacements per day (LSM $\pm \mathrm{SE}$ ), whereas the $100 \mathrm{D}$ pen averaged 21.3 \pm 1.0 displacements per day $(P<0.01$; Figure 2$)$.

\section{Feeding Behavior}

Treatment and parity interacted (Figure $3 ; P=$ 0.003). Overall, parous animals spent $46.9 \pm 6.6 \mathrm{~min} / \mathrm{d}$ more time feeding than nulliparous animals $(P<0.01)$.

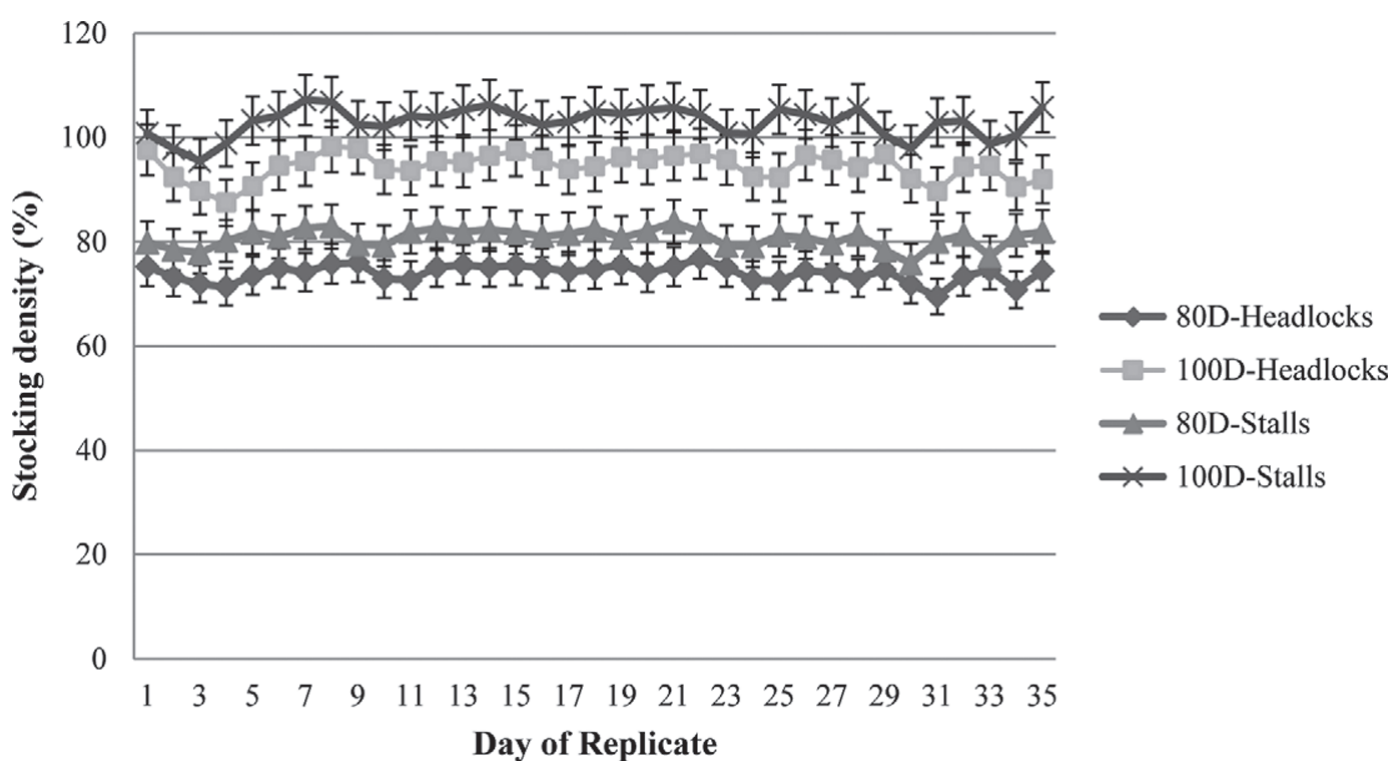

Figure 1. Average stocking density based on the number of headlocks and number of stalls according to treatment. This study had 8 experimental units $(4$ replicates $\times 2$ pens/treatment per replicate). Treatments: $80 \mathrm{D}=$ cows housed in prepartum pens with $80 \%$ target stocking density (38 cows per pen; each pen with 48 headlocks and 44 stalls); 100D = cows housed in prepartum pens with $100 \%$ target stocking density (48 cows per pen). Headlocks: $80 \mathrm{SD}=74.1 \pm 0.4 \%, 100 \mathrm{SD}=94.5 \pm 0.3 \%(P<0.01)$; stalls: $80 \mathrm{SD}=80.8 \pm 0.4 \%, 100 \mathrm{SD}=103.1 \pm 0.4 \%(P$ $<0.01$ ); error bars represent SEM. 


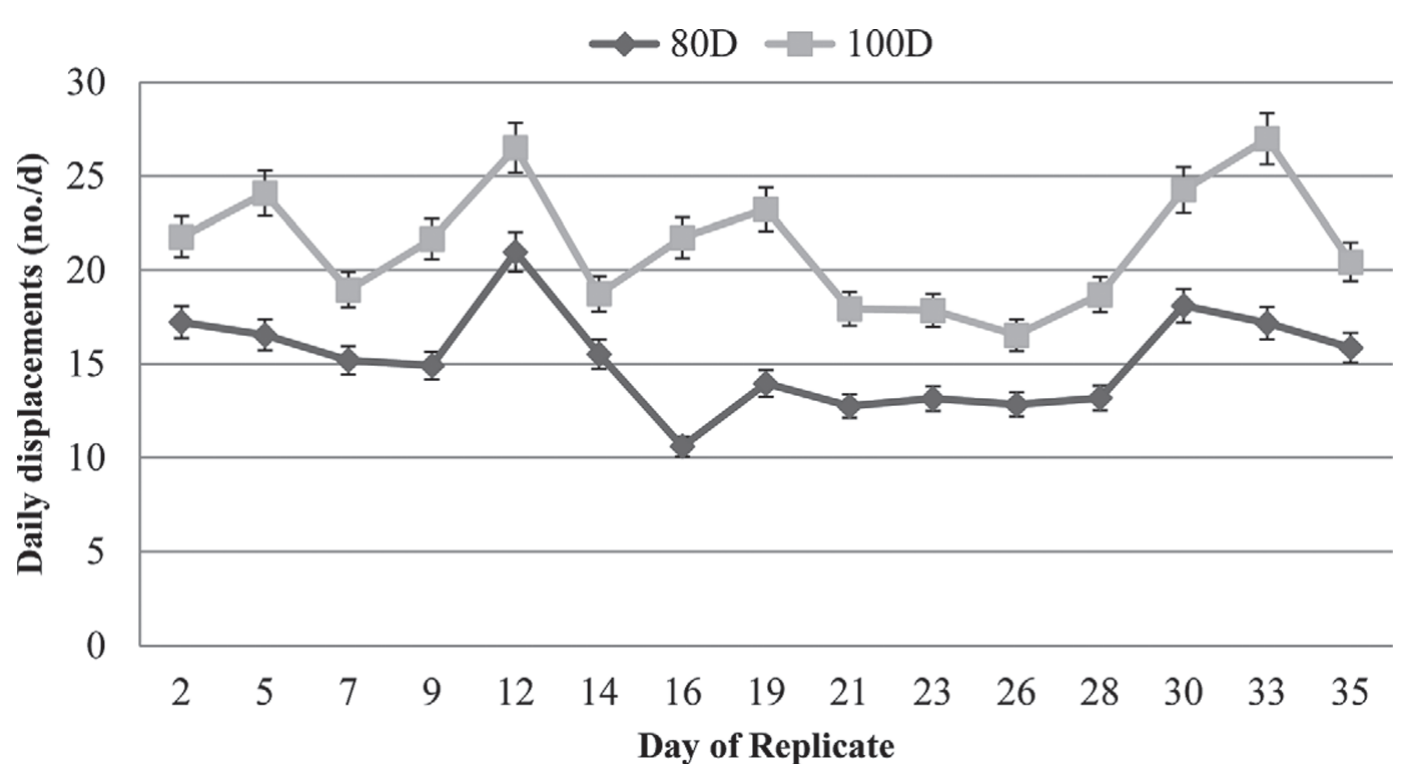

Figure 2. Mean daily displacements from the feed bunk for treatments. Treatments: $80 \mathrm{D}=$ cows housed in prepartum pens with $80 \%$ target stocking density (38 cows per pen; each pen with 48 headlocks and 44 stalls); 100D = cows housed in prepartum pens with $100 \%$ target stocking density (48 cows per pen). This study had 8 experimental units $(4$ replicates $\times 2$ pens/treatment per replicate). Treatment affected the mean $( \pm \mathrm{SEM})$ of the number of displacements from the feed bunk $(80 \mathrm{D}=15.2 \pm 1.0,100 \mathrm{D}=21.3 \pm 1.0 ; P<0.001)$.

Mean daily feeding times for parous 100D, parous 80D, nulliparous $100 \mathrm{D}$, and nulliparous $80 \mathrm{D}$ were $293.6 \pm$ $5.1,301.2 \pm 5.4,256.7 \pm 5.2$, and $244.3 \pm 5.5 \mathrm{~min} / \mathrm{d}$, respectively. Nulliparous animals at 100D stocking density spent $12.4 \pm 5.0$ more minutes per day feeding than 80D nulliparous animals $(P=0.013)$, whereas 100D parous animals tended to spend $7.6 \pm 4.5$ fewer minutes per day feeding than $80 \mathrm{D}$ parous animals $(P$ $=0.095)$.

\section{Relationship Between Social Rank and Daily Feeding Time}

Treatment, parity, and social rank interacted for daily feeding time. Social rank was not associated with feeding time among 80D nulliparous, 100D nulliparous, and $80 \mathrm{D}$ parous animals. However, middle-ranking parous animals housed in 100D spent $27.2 \pm 8.7(P=$ $0.002)$ and $15.0 \pm 7.4(P=0.042)$ more minutes per day eating than high- and low-ranking animals, respectively (Table 1). High- and low-ranking 100D parous animals did not differ in their daily feeding time.

\section{Lying Behavior}

Both 80D and 100D animals spent $13.0 \pm 0.1 \mathrm{~h} / \mathrm{d}$ lying down (LSM $\pm \mathrm{SE} ; P>0.05)$. Nulliparous animals spent $0.4 \pm 0.2 \mathrm{~h} / \mathrm{d}$ less time lying down than multiparous animals $(12.9 \pm 0.1$ and $13.2 \pm 0.1$, respectively; $P=0.028)$. A treatment $\times$ day relative to calving effect was observed (Figure $4 ; P=0.004$ ). Animals (nulliparous and parous) stocked at 100D had longer lying times than $80 \mathrm{D}$ on $\mathrm{d}-33,-29$, and -26 , with a tendency $(P=0.081)$ on $\mathrm{d}-24$ prepartum. On $\mathrm{d}$ $-7,-5$ and $0,80 \mathrm{D}$ had longer lying times than 100D animals $(P<0.05)$.

The $80 \mathrm{D}$ and 100D treatments were not different for number of lying bouts per day $(15.3 \pm 0.5$ and $14.9 \pm$ 0.5 , respectively). Nulliparous animals had more $(P<$ $0.01)$ lying bouts per day $(16.5 \pm 0.5)$ than parous animals $(13.7 \pm 0.5)$. Lying-bout duration did not differ between the $80 \mathrm{D}$ or $100 \mathrm{D}$ stocking-density treatments $(1.1 \pm 0.03 \mathrm{~h}$ per bout). Lying-bout duration differed between nulliparous and parous animals $(P<0.01)$. Lying-bout duration for nulliparous animals was 0.35 $\pm 0.04 \mathrm{~h}$ per bout less than parous animals $(0.9 \pm 0.03$ and $1.3 \pm 0.03 \mathrm{~h}$ per bout, respectively).

\section{Relationship Between Social Rank and Lying Behavior Variables}

The interaction among treatment, parity, and social rank was associated with lying time $(P=0.024$; Table 2 ). High-ranking parous animals in the $80 \mathrm{D}$ stocking density spent $1.0 \pm 0.4 \mathrm{~h} / \mathrm{d}$ less time lying down than middle-ranking animals $(P=0.017)$ and did not differ from low-ranking animals. No differences were observed in daily lying time for middle- and low-ranking 80D parous animals. Middle-ranking 100D nulliparous animals spent $0.8 \pm 0.3(P=0.016)$ and tended to spend 
Table 1. Feeding times $(\mathrm{min} / \mathrm{d}$; means $\pm \mathrm{SE})$ during the prepartum period according to parity (parous vs. nulliparous), treatment (80D vs. 100D), ${ }^{1}$ and social-rank category

\begin{tabular}{lccc}
\hline & \multicolumn{3}{c}{ Social-rank category $^{2}$} \\
\cline { 2 - 4 } Item & High & Middle & Low \\
\hline Parous $^{3}$ & & & \\
80D & $300.7 \pm 7.4$ & $301.3 \pm 6.2$ & $294.9 \pm 5.9$ \\
100D & $272.7 \pm 6.8^{\mathrm{a}}$ & $300.0 \pm 5.6^{\mathrm{b}}$ & $284.9 \pm 4.9^{\mathrm{a}}$ \\
Nulliparous & & & \\
80D & $255.3 \pm 8.5$ & $250.1 \pm 6.2$ & $238.1 \pm 7.0$ \\
100D & $265.9 \pm 8.5$ & $256.4 \pm 5.4$ & $258.9 \pm 6.0$ \\
\hline
\end{tabular}

${ }^{\mathrm{a}, \mathrm{b}}$ Means within a row with different superscripts differ $(P<0.05)$.

${ }^{1} 80 \mathrm{D}=$ animals housed in prepartum pens with $80 \%$ stocking density (38 cows per pen); 100D = animals housed in prepartum pens with $100 \%$ stocking density (48 cows per pen; each pen with 48 headlocks and 44 stalls).

${ }^{2}$ The displacement index (DI) for each cow was calculated as the number of displacements as actor divided by total displacements. Social categories were low: DI $<0.40$; middle: $0.40 \leq \mathrm{DI} \leq 0.60$; and high: DI $>0.60$.

${ }^{3}$ Parous animals were a mix of prepartum lactations $\geq 1$ and were housed separately from nulliparous animals.

$0.7 \pm 0.4(P=0.089)$ fewer hours per day lying down than low- and high-ranking nulliparous animals, respectively. High- and low-ranking 100D nulliparous animals did not differ in daily lying time.

The interaction between treatment and social rank did not affect number of lying bouts per day or lyingbout duration; however, differences existed between parities. High-ranking parous animals had fewer lying bouts per day $(P=0.034)$ than middle-ranking animals $(12.3 \pm 0.9$ vs. $14.8 \pm 0.7$ lying bouts per day) and did not differ $(P=0.11)$ from low-ranking animals $(14.2 \pm$ 0.8 ). Middle- and low-ranking parous animals did not differ in the number of lying bouts per day. Nulliparous animals averaged $18.4 \pm 0.9,16.0 \pm 0.7$, and $16.5 \pm 0.8$ lying bouts per day for high, middle, and low ranking, respectively. High-ranking nulliparous animals averaged $2.4 \pm 1.1$ more bouts than middle-ranking animals $(P$ $=0.038$ ) and did not differ from low-ranking animals. Middle- and low-ranking nulliparous animals did not differ in the number of lying bouts per day.

The lying-bout duration (hours per bout) of highranking parous animals was longer than middle-ranking animals $(1.4 \pm 0.06$ vs. $1.2 \pm 0.05 ; P=0.049)$ and tended to be longer than low-ranking parous animals $(1.2 \pm 0.05 ; P=0.079)$. No differences were observed between middle- and low-ranking parous animals for lying-bout duration. Social rank was not associated with lying-bout duration for nulliparous animals and averaged $0.9 \pm 0.5 \mathrm{~h}$ per bout.

\section{DISCUSSION}

The purpose of this study was to replicate conditions commonly observed on commercial dairy farms with the addition of new animals to the prepartum pen, which

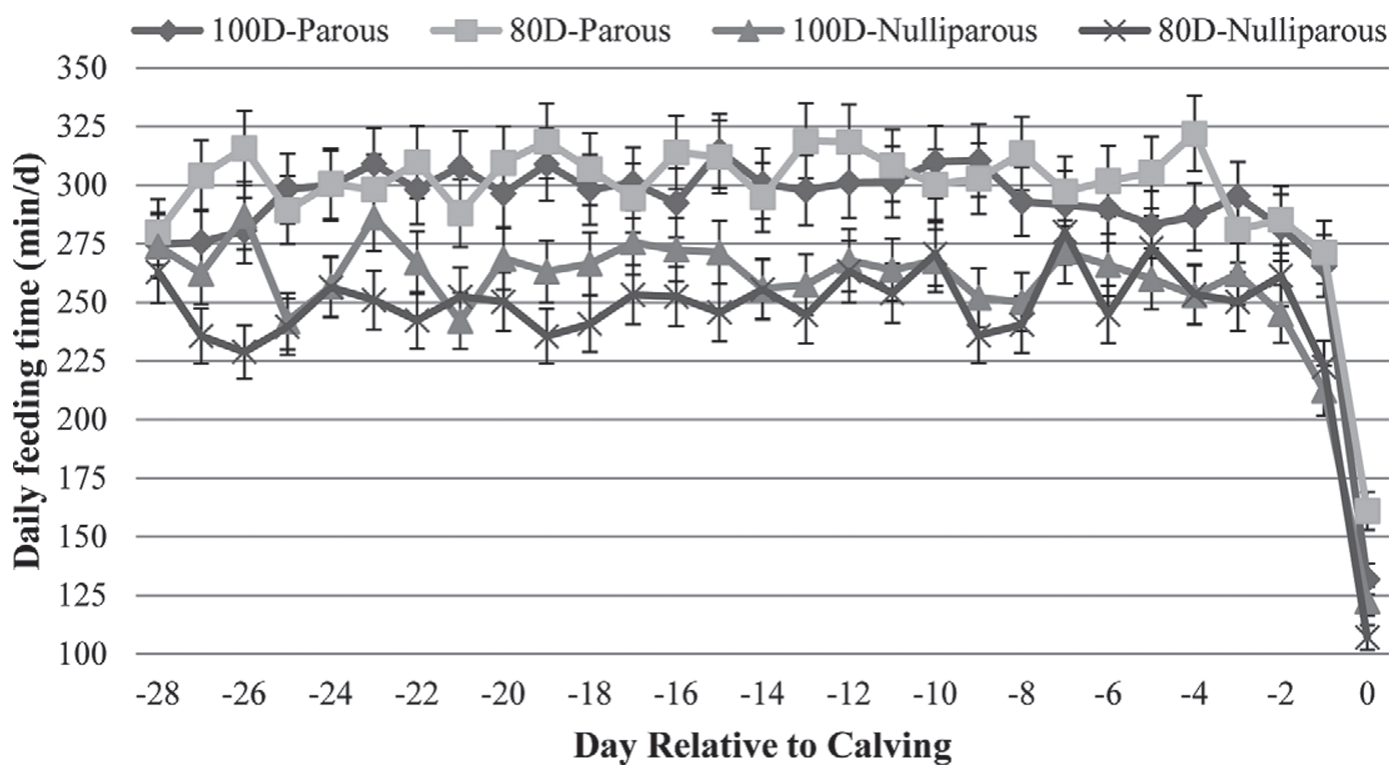

Figure 3. Mean daily feeding times for 80 (80D) and 100\% (100D) prepartum stocking density relative to calving. This study had 8 experimental units $(4$ replicates $\times 2$ pens/treatment per replicate). Treatments: $80 \mathrm{D}=$ cows housed in prepartum pens with $80 \%$ target stocking density (38 cows per pen; each pen with 48 headlocks and 44 stalls); 100D = cows housed in prepartum pens with $100 \%$ target stocking density (48 cows per pen). Overall, 80D nulliparous animals spent $12.4 \pm 5.0$ less minutes per day feeding than 100D nulliparous animals $(P<0.05)$. Parous 80D (prepartum lactation $\geq 1$ ) animals tended to spend $7.6 \pm 4.5$ more minutes per day feeding than 100D parous animals $(P=0.095)$. Error bars represent SE. 
Table 2. Lying time (h/d; means $\pm \mathrm{SE})$ during the prepartum period according to parity, treatment $(80 \mathrm{D}$ vs. $100 \mathrm{D}),{ }^{1}$ and social-rank category

\begin{tabular}{lccc}
\hline & \multicolumn{3}{c}{ Social-rank category $^{2}$} \\
\cline { 2 - 4 } Item & High & Middle & Low \\
\hline Parous $^{3}$ & $12.6 \pm 0.3^{\mathrm{a}}$ & $13.5 \pm 0.3^{\mathrm{b}}$ & $13.2 \pm 0.3^{\mathrm{ab}}$ \\
80D & $13.0 \pm 0.3$ & $13.2 \pm 0.3$ & $13.6 \pm 0.2$ \\
100D & & & \\
Nulliparous & $13.3 \pm 0.3$ & $13.1 \pm 0.3$ & $12.7 \pm 0.3$ \\
80D & $13.1 \pm 0.3^{\mathrm{ab}_{\dagger}}$ & $12.4 \pm 0.3^{\mathrm{b}} \dagger$ & $13.2 \pm 0.3^{\mathrm{a}}$ \\
100D &
\end{tabular}

${ }^{\mathrm{a}, \mathrm{b}}$ Means within a row with different superscripts differ $(P<0.05)$.

${ }^{1} 80 \mathrm{D}=$ animals housed in prepartum pens with $80 \%$ stocking density (38 cows per pen); 100D = animals housed in prepartum pens with $100 \%$ stocking density ( 48 cows per pen; each pen with 48 headlocks and 44 stalls).

${ }^{2}$ The displacement index (DI) for each cow was calculated as the number of displacements as actor divided by total displacements. Social categories were low: DI $<0.40$; middle: $0.40 \leq$ DI $\leq 0.60$; and high: DI $>0.60$.

${ }^{3}$ Parous animals were a mix of prepartum lactations $\geq 1$ and were housed separately from nulliparous animals.

$\dagger$ High- and middle-ranking nulliparous animals tend to differ $(P<$ $0.10)$.

creates socially unstable groups and reduces stall, feedbunk, and overall pen space as pen density increases. Our results confirm previous research indicating that when more space was provided at the feed bunk, the number of displacements during the $3 \mathrm{~h}$ after fresh feed delivery was reduced, regardless of parity. Several stud- ies have demonstrated that increasing stocking density affects feeding and lying behavior (Olofsson, 1999; DeVries et al., 2004; Proudfoot et al., 2009). DeVries et al. (2004) reported reduced aggressive interactions and increased feeding activity after fresh feed delivery when feed bunk space was increased from 0.5 to $1.0 \mathrm{~m}$ per cow. Hill et al. (2009) did not notice an increase in displacements from the feed bunk with 4 stocking densities ranging from 100 to $142 \%$. They maintained pen size, but blocked access to stalls and headlocks to achieve the desired stocking density. Additionally, groups were kept socially stable, which may contribute to a reduction on the number of displacements from the feed bunk. Lobeck-Luchterhand et al. (2014) reported fewer displacements from the feed bunk for close-up prepartum animals housed in a socially stable group versus a pen with weekly entrances of new animals, and this difference was still apparent even after accounting for differences in pen stocking density.

Because of the different nutrient demands of nulliparous animals compared with the rest of the herd, some large commercial dairies house nulliparous animals separately from parous animals. In our study nulliparous and parous animals were housed separately per protocol of the dairy. Boyle et al. (2013) reported that nulliparous animals mixed with multiparous animals prepartum received fewer butts and had greater locomotion than nulliparous animals housed with other nulliparous animals. Most of our differences in lying

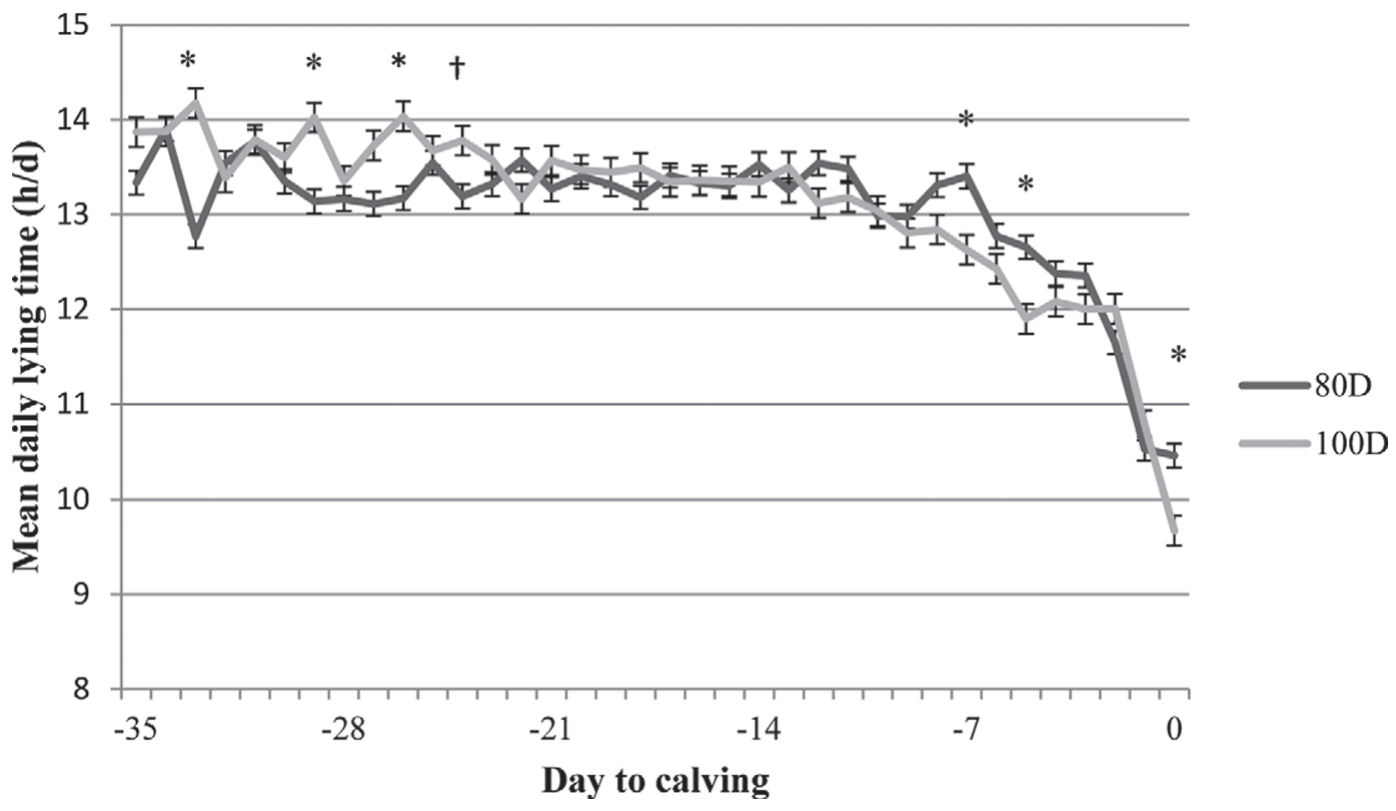

Figure 4. Mean daily lying times for 80 (80D) and 100\% (100D) prepartum stocking density. This study had 8 experimental units (4 replicates $\times 2$ pens/treatment per replicate). Treatments: $80 \mathrm{D}=$ cows housed in prepartum pens with $80 \%$ target stocking density $(38$ cows per pen; each pen with 48 headlocks and 44 stalls); $100 \mathrm{D}=$ cows housed in prepartum pens with $100 \%$ target stocking density (48 cows per pen). *Significant differences between treatments $(P<0.05)$. $\dagger$ Denotes a tendency between treatments $(P<0.10)$. Treatments differed in lying time on $\mathrm{d}-33,-29-26,-7,-5$, and 0 . Error bars represent SE. 
behavior can be attributed to the nulliparous animals and their tendency to be more mobile than their older counterparts (locomotion score at enrollment $1.0 \pm$ 0.01 vs. $1.1 \pm 0.01 ; P<0.001)$. Nulliparous animals spent less time lying down per day and had shorter lying-bout duration with more lying bouts per day than parous animals. Boyle et al. (2013) reported that lying behavior (lying time, number of lying bouts, and lyingbout duration) did not differ in nulliparous animals that were mixed with multiparous animals compared with nulliparous animals housed with other nulliparous animals during the $3 \mathrm{wk}$ prepartum and stocked at $100 \%$ of stalls.

Prepartum animals in this study were housed in pens with stall stocking density averaging $103.1 \%$ (maximum of $109 \%$ ), and overall lying behavior was not adversely affected compared with animals housed at $80.8 \%$. However, animals in the $80 \mathrm{D}$ treatment spent more time lying down near parturition than 100D animals, whereas earlier in the prepartum period, the opposite was observed, with 100D animals lying down longer than $80 \mathrm{D}$. These results could indicate that cows normally compete and gain access to the stalls when stocked at higher densities, but near parturition when lying times normally are reduced, under stocking is protective and allows cows to maintain lying time for a longer period. Hill et al. (2009) reported as pen stocking density (headlocks and stalls) of a mixed pen of multiparous and primiparous cows increased from 100 up to $142 \%$, the percentage of cows and time spent lying decreased. Similarly, Fregonesi et al. (2007) reported lying time was reduced by $2 \mathrm{~h} / \mathrm{d}$ when stocking density of stalls was increased from 100 to $150 \%$. Krawczel et al. (2012) reported a decrease in lying time when stocking density exceeded $131 \%$ compared with 100 and $113 \%$. The time budgets of prepartum cows tend to be interrupted less than lactating dairy cows. Data from lactating dairy cows on commercial herds showed that as the number of cows in the pen increased, lying daily bout frequency increased and lying-bout duration decreased (Charlton et al., 2014). Based on our results and previous studies, it appears that lying time is not significantly affected for prepartum cows up to $103 \%$ of stall stocking density.

Stocking animals at $100 \%$ had a tendency to affect mean daily feeding times. Nulliparous animals stocked at $100 \%$ spent a longer time feeding than nulliparous animals stocked at $80 \%$. The opposite tended to be observed, with parous animals stocked at $100 \%$ spending less time eating than parous animals stocked at $80 \%$. These results tend to contrast with Hill et al. (2009) and Krawczel et al. (2012), who found no differences in mean daily feeding time for lactating cows at 4 stocking densities of $110,113,131$, or $142 \%$. Significant differences in mean feeding times were observed between nulliparous and parous animals, which in the current experiment were housed separately. In the previous studies mentioned, nulliparous and parous animals were housed together, and this could be one reason for contrasting results. Azizi et al. (2009) also reported that prepartum nulliparous animals spent less time eating than parous animals, which was also observed for earlylactation cows. Future work should document priority of access to the 2 resources (stalls and feed) separately and with mixed and separate parity groups.

An additional analysis was conducted to determine whether certain social groups of animals were affected by the increased competition for feed and lying space. Differences were noticed between treatment and parity. Nulliparous animals housed at either 80 or $100 \%$ stocking density did not differ in daily feeding times; however, middle-ranking parous animals spent more time feeding than both high- and low-ranking animals. Huzzey et al. (2006) reported feeding time increased when stocking density decreased, and this was most apparent in lower ranking cows. Proudfoot et al. (2009) observed competition had a tendency to decrease feed intake of prepartum multiparous cows the week before calving, although postpartum intakes did not differ. Olofsson (1999) observed DMI increased as competition increased, and this was driven by an increased feeding rate (Olofsson, 1999). In the current study, DMI data were not collected because the experiment was conducted in a commercial dairy.

Studies have shown that when competition increased, standing time increased (Huzzey et al., 2006) and daily lying time decreased (Fregonesi et al., 2007). Highranking parous animals spent less time lying down in the $80 \mathrm{D}$ treatment and had fewer and longer lying bouts than middle-ranking animals. Middle-ranking nulliparous animals at 100D spent less time lying down than both high- and low-ranking animals, and this was attributed to the decrease in the number of lying bouts. Although animals in this experiment were categorized on rank according to their ability to access the feed bunk, Val-Laillet et al. (2008) reported individual measurements of success to displace another cow were not highly correlated with the 3 resources tested: feed alley, stalls, and rotating brush. In a study evaluating social hierarchy on cow use of shade and water, social hierarchy did not influence drinking behavior when the water trough was inside the paddock; however, when the water trough was located in the alley, the number of drinking events and the time spent drinking were greater for dominant cows in comparison to subordinate cows (Coimbra et al., 2012). Social hierarchy did not influence the number of visits or the time spent in the shade, irrespective of the location of the water trough (Coimbra et al., 2012). The average feeding time of low- 
er-ranked cows was significantly longer than dominant cows (Hasegawa et al., 1997). The use of feed barriers increased cow feeding time and decreased the number of feeding bouts in relation to the total time feed was available and was notably observed in subordinate cows (Hetti Arachchige et al., 2014). It appears social rank may alter prepartum animal behavior for both feeding and lying resources; social-rank relationships are complicated and still not completely understood.

We found in a previous study that reducing stocking density for close-up prepartum animals from 100 to $80 \%$ did not result in fewer health events, increased milk yield, or greater percentage of animals diagnosed pregnant after first postpartum AI (Silva et al., 2014). In addition, we observed no differences between the 80 and $100 \%$ stocking densities for number of animals removed from the herd or metabolic parameters (Silva et al., 2014). Our evaluation of a subgroup of animals for the effect of prepartum stocking density on immune parameters showed no differences between treatments for polymorphonuclear leukocyte count or phagocytic activity (Dresch et al., 2013). Other research groups showed similar results. Stocking rate did not affect pregnancy rates, immunological parameters, or health status of grazing dairy cattle (McCarthy et al., 2012). Boyle et al. (2013) reported no differences in milk production for nulliparous cows mixed with multiparous cows when compared with an all-nulliparous pen stocked at $100 \%$.

Most studies during the transition period involved Holstein cows (Huzzey et al., 2005; Proudfoot et al., 2009; Krawczel et al., 2012). Olson et al. (2011) reported that Holstein-Jersey cows had significantly greater odds of mastitis than pure Holstein cows, whereas there was a trend for Holstein-Jersey cows to have lower odds of metritis than pure Holstein cows. The incidence of transition health events were displaced abomasum, 14 versus $0 \%$; ketosis, 9 versus $9 \%$; mastitis, 2 versus $27 \%$; and metritis, 19 vs. $0 \%$ in 43 Holstein and 22 purebred Jersey cows, respectively (Olson et al., 2011). Holstein cows had greater days open than Jerseys (169 vs. 132 d), whereas Jerseys had a higher frequency of mastitis than Holsteins (10.3 vs. $1.1 \%$, respectively; Brown et al., 2012). Holstein cows mobilized more body energy in early lactation than Danish Red or Jerseys (Friggens et al., 2007). To our knowledge this is the first stocking-density study of prepartum Jersey cows in a commercial setting evaluating behavior.

\section{CONCLUSIONS}

Housing Jersey prepartum animals at 100\% stocking density increased negative social behaviors, affected lying behavior differently depending on time before parturition, increased daily feeding time of nulliparous animals, and had a tendency to reduce daily feeding time of parous animals compared with $80 \%$ stocking density. Social rank was associated with feeding and lying behaviors, and this association varied depending on parity and stocking density. Therefore, although these results showed some potential behavior benefits of a low prepartum stocking density of $80 \%$, more research is needed to evaluate the effect of stocking densities greater than $100 \%$ and with other breeds of dairy cattle, such as Holstein.

\section{ACKNOWLEDGMENTS}

The authors thank the owner, manager, and staff of New Sweden Dairy (Nicollet, MN) for allowing us to use their facility and animals. In addition, the authors thank A. Dresch, H. Hooper, J. Moraes, K. Machado, T. Nishimura, and M. Ferreira (all from University of Minnesota, St. Paul) for their help with the animal movements in coordination with the project; M. Q. Shahid, T. Evink, M. Jorgensen, A. Adams-Progar, S. Fessenden, J. Johnson, and A. Hazel (all from University of Minnesota, St. Paul) for help with applying hair dye and animal recording; and A. Plumski, E. Boser, R. Johnson, A. Schwartau, and K. McNab (all from University of Minnesota, St. Paul) for feeding behavior video analysis. This experiment was partially funded by a University of Minnesota Rapid Agriculture Response Fund Grant and Novus International (St. Charles, MO).

\section{REFERENCES}

Azizi, O., O. Kaufmann, and L. Hasselmann. 2009. Relationship between feeding behavior and feed intake of dairy cows depending on their parity and milk yield. Livest. Sci. 122:156-161.

Boyle, A. R., C. P. Ferris, and N. E. O'Connell. 2013. Does housing nulliparous dairy cows with multiparous animals prior to calving influence welfare- and production-related parameters after calving? Appl. Anim. Behav. Sci. 143:1-8.

Brown, K. L., B. G. Cassell, M. L. McGilliard, M. D. Hanigan, and F. C. Gwazdauskas. 2012. Hormones, metabolites and reproduction in Holsteins, Jerseys and their crosses. J. Dairy Sci. 95:698-707.

Charlton, G. L., D. B. Haley, J. Rushen, and A. M. de Passillé. 2014. Stocking density, milking duration, and lying times of lactating cows on Canadian freestall dairy farms. J. Dairy Sci. 97:26942700.

Coimbra, P. A. D., L. C. P. M. Filho, and M. J. Hötzel. 2012. Effects of social dominance, water trough location and shade availability on drinking behavior of cows on pasture. Appl. Anim. Behav. Sci. 139:175-182.

Collings, L. K. M., D. M. Weary, N. Chapinal, and M. A. G. von Keyserlink. 2011. Temporal feed restriction and overstocking increase competition for feed by dairy cattle. J. Dairy Sci. 94:5480-5486.

Cook, N. B., T. B. Bennett, and K. V. Nordlund. 2004. Effect of free stall surface on daily activity patterns in dairy cows with relevance to lameness prevalence. J. Dairy Sci. 87:2912-2922.

DeVries, T. J., M. A. G. von Keyserlingk, and D. M. Weary. 2004. Effect of feeding space on the inter-cow distance, aggression, and feeding behavior of free-stall housed lactating dairy cows. J. Dairy Sci. 87:1432-1438. 
Dresch, A. R., J. Moraes, P. Silva, H. Hooper, C. Spies, P. Lau, K. M. Lobeck, K. Machado, M. Ballou, M. I. Endres, and R. C. Chebel. 2013. Effect of stocking density in the prepartum period on innate immune parameters and hemogram of dairy cows. J. Dairy Sci. 96(E-Suppl. 1):46.

Endres, M. I., T. J. DeVries, M. A. G. von Keyserlingk, and D. M. Weary. 2005. Effect of feed barrier design on the behavior of loosehoused lactating dairy cows. J. Dairy Sci. 88:2377-2380.

Fregonesi, J. A., C. B. Tucker, and D. M. Weary. 2007. Overstocking reduces lying time in dairy cows. J. Dairy Sci. 90:3349-3354.

Friggens, N. C., P. Berg, P. Theilgaard, I. R. Korsgaard, K. L. Ingvartsen, P. Løvendahl, and J. Jensen. 2007. Breed and parity effects on energy balance profiles through lactation: Evidence of genetically driven body energy change. J. Dairy Sci. 90:5291-5305.

Galindo, F., and D. M. Broom. 2000. The relationships between social behavior of dairy cows and the occurrence of lameness in three herds. Res. Vet. Sci. 69:75-79.

Godden, S. M., S. C. Stewart, J. F. Fetrow, P. Rapnicki, R. Cady, W. Weiland, H. Spencer, and S. W. Eicker. 2003. The relationship between rbST-supplementation and other factors and risk for removal for cows in Minnesota Holstein dairy herds. Pages 55-64 in Proc. Four-State Nutr., LaCrosse, WI. MidWest Plan Serv. (MWPS) Publ. MWPS-4SD16. MWPS, Ames, IA.

Goff, J. P., and R. L. Horst. 1997. Physiological changes at parturition and their relationship to metabolic disorders. J. Dairy Sci. 80:1260-1268.

Grummer, R. R. 1995. Impact of changes in organic nutrient metabolism on feeding the transition dairy cow. J. Anim. Sci. 73:28202833.

Hasegawa, N., A. Nishiwaki, K. Sugawara, and I. Ito. 1997. The effects of social exchange between two groups of lactating primiparous heifers on milk production, dominance order, behavior, and adrenocortical response. Appl. Anim. Behav. Sci. 51:15-27.

Hayirli, A., R. R. Grummer, E. V. Nordheim, and P. M. Crump. 2002. Animal and dietary factors affecting feed intake during the prefresh transition period in Holsteins. J. Dairy Sci. 85:3430-3443.

Hetti Arachchige, A. D., A. D. Fisher, W. J. Wales, M. J. Auldist, M. C. Hannah, and E. C. Jongman. 2014. Space allowance and barriers influence cow competition for mixed rations fed on a feed-pad between bouts of grazing. J. Dairy Sci. 97:3578-3588.

Hill, C. T., P. D. Krawczel, H. M. Dann, C. S. Ballard, R. C. Hovey, W. A. Falls, and R. J. Grant. 2009. Effect of stock density on the short-term behavioural responses of dairy cows. Appl. Anim. Behav. Sci. 117:144-149.

Hosseinkhani, A., T. J. DeVries, K. L. Proudfoot, R. Valizadeh, D. M. Veira, and M. A. G. von Keyserlingk. 2008. The effects of feed bunk competition on the feed sorting behavior of close-up dry cows. J. Dairy Sci. 91:1115-1121.

Huzzey, J. M., T. J. DeVries, P. Valois, and M. A. G. von Keyserlingk. 2006. Stocking density and feed barrier design affect the feeding and social behavior of dairy cattle. J. Dairy Sci. 89:126-133.

Huzzey, J. M., D. V. Nydam, R. J. Grant, and T. R. Overton. 2012. The effects of overstocking Holstein dairy cattle during the dry period on cortisol secretion and energy metabolism. J. Dairy Sci. 95:4421-4433.
Huzzey, J. M., M. A. G. von Keyserlingk, and D. M. Weary. 2005. Changes in feeding, drinking, and standing behavior of dairy cows during the transition period. J. Dairy Sci. 88:2454-2461.

Krawczel, P. D., L. B. Klaiber, R. E. Butzler, L. M. Klaiber, H. M. Dann, C. S. Mooney, and R. J. Grant. 2012. Short-term increases in stocking density affect the lying and social behavior, but not the productivity, of the lactating Holstein dairy cows. J. Dairy Sci. 95:4298-4308.

Ledgerwood, D. N., C. Winckler, and C. B. Tucker. 2010. Evaluation of data loggers, sampling intervals, and editing techniques for measuring the lying behavior of dairy cattle. J. Dairy Sci. 93:5129-5139.

Lobeck-Luchterhand, K. M., P. B. R. Silva, R. C. Chebel, and M. I. Endres. 2014. Effect of prepartum grouping strategy on displacements from the feed bunk and feeding behavior of dairy cows. J. Dairy Sci. 97:2800-2807.

McCarthy, B., K. M. Pierce, L. Delaby, A. Brennan, and B. Horan. 2012. The effect of stocking rate and calving date on reproductive performance, body state, and metabolic and health parameters of Holstein-Friesian dairy cows. J. Dairy Sci. 95:1337-1348.

Munksgaard, L., M. B. Jensen, L. J. Pedersen, S. W. Hansen, and L. Matthews. 2005. Quantifying behavioural priorities-Effects of time constraints on behaviour of dairy cows, Bos taurus. Appl. Anim. Behav. Sci. 92:3-14.

Nordlund, K., N. Cook, and G. Oetzel. 2006. Commingling dairy cows: Pen moves, stocking density, and health. Pages 36-42 in 39th Proc. Am. Assoc. Bovine Pract., St. Paul, MN. Bovine Practitioner, Opelika, AL.

Oetzel, G. R., K. M. Emery, W. P. Kautz, and J. E. Nocek. 2007. Direct-fed microbial supplementation and health and performance of pre- and postpartum dairy cattle: A field trial. J. Dairy Sci. 90:2058-2068.

Olofsson, J. 1999. Competition for total mixed diets fed for ad libitum intake using one or four cows per feeding station. J. Dairy Sci. 82:69-79

Olson, K. M., B. G. Cassell, M. D. Hanigan, and R. E. Pearson. 2011. Short communication: Interaction of energy balance, feed efficiency, early lactation health events, and fertility in first-lactation Holstein, Jersey, and reciprocal $\mathrm{F}_{1}$ crossbred cows. J. Dairy Sci. 94:507-511.

Proudfoot, K. L., D. M. Veira, D. M. Weary, and M. A. G. von Keyserlingk. 2009. Competition at the feed bunk changes the feeding, standing, and social behavior of transition cows. J. Dairy Sci. 92:3116-3123.

Silva, P. R., A. R. Dresch, K. S. Machado, K. Lobeck-Luchterhand, T. K. Nishimura, M. A. Ferreira, M. I. Endres, and R. C. Chebel. 2014. Prepartum stocking density: Effects on metabolic, health, reproductive, and productive parameters. J. Dairy Sci. 97:55215532.

Telezhenko, E., M. A. G. von Keyserlingk, A. Talebi, and D. M. Weary. 2012. Effect of pen size, group size, and stocking density on activity in freestall-housed dairy cows. J. Dairy Sci. 95:3064-3069.

Val-Laillet, D., D. M. Veira, and M. A. G. von Keyserlingk. 2008. Short communication: Dominance in free-stall housed dairy cattle is dependent on resource. J. Dairy Sci. 91:3922-3926. 